\title{
Triple-Shell NiO Hollow Sphere for p-Type Dye-Sensitized Solar Cell with Superior Light Harvesting
}

Jie $\mathrm{Qu}^{\mathrm{a}}$, Ke Zhang ${ }^{\mathrm{a}}$, Hany Gamal ${ }^{\mathrm{b}}$, Jiannan Wang c,*, Amor M. Abdelkader ${ }^{\mathrm{d}, *}$

a College of Chemistry and Chemical Engineering, Hunan Normal University, Changsha 410081, China

b Nuclear Materials Authority, Maadi, Cairo 11381, Egypt

c Department of Environmental Science and Engineering, State Key Laboratory of Multiphase Flow in Power Engineering, Xi'an Jiaotong University, Xi'an 710049, China

d Faculty of Science and Technology, Bournemouth University, Poole, Dorset BH12 5BB, UK

* Corresponding author.

E-mail address: wangjn116@,xjtu.edu.cn (J. Wang)

E-mail address: aabdelkader@bournemouth.ac.uk (AMA.)

\begin{abstract}
In this article, new p-DSSC electrodes are fabricated using NiO hollow spheres (HSs) prepared through a facial one-step hydrothermal process. The current-voltage (J-V) curve indicates that p-DSSCs fabricated using triple-shell NiO HS have excellent photoelectrochemical performance, with a photoelectrical efficiency of $1.79 \%$. The UV-vis diffused reflectance spectra indicate that the triple-shell $\mathrm{NiO} \mathrm{HS}$, with its unique structure, has superior light reflection, scattering ability and large surface area with more inner cavities, which helps harvest more light. Electrochemical impedance
\end{abstract}


spectroscopy (EIS) further confirms that triple-shell NiO HS shows fast dye regeneration, improved hole transport and suppressed recombination. The research work of unique $\mathrm{NiO} \mathrm{HS}$ is important for the selection of efficient photocathode materials for $\mathrm{p}$-DSSCs.

Keywords: NiO; Hollow spheres; Light-harvesting; Transfer kinetics; Solar cell

\section{Introduction}

Recently, dye-sensitized solar cells (DSSCs) are receiving increasing attention because of their potential for a low cost and high efficient energy conversion (Grätzel, 2001; Mansha et al., 2019; Naveen Kumar et al., 2020; Qu et al., 2010; Qu et al., 2014;

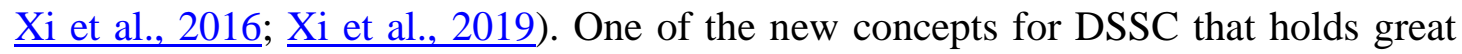
potential is the p-n tandem design, which uses an n-DSSC (photoanode sensitized) and a p-DSSC (photocathode sensitized) (Jianjun He, 1999; Nattestad et al., 2010) stacked in series. The theoretical efficiency of tandem DSSC can reach up to $43 \%$, higher than single electrode DSSC (33\%). However, the actual efficiency reported so far for tandem DSSC is much lower than the theoretical value mainly due to the low photoelectrical performance (low voltage and low current) of the p-DSSC. Unlike n-DSSC, photogenerated holes are injected into the valence band of the p-type semiconductor and transferred to the FTO. The reduced dyes are oxidized by the redox electrolyte, diffuses to the counter electrode and further oxidized by the holes from the external circuit (Qu et al., 2020; Tan et al., 2019). NiO is the most commonly used hole transporter in photocathode, which shows a wideband gap of 3.5 
eV with excellent chemical and thermal stability (Awais et al., 2012; Jianjun He, 1999; Nattestad et al., 2008; Zhang et al., 2011). Obviously, the structural features of the $\mathrm{NiO}$ films, such as morphology and porosity, have a significant influence on the stability, transparency and the penetration depth of the light (Bonomo et al., 2018; $\underline{\text { Liu }}$ et al., 2015a; Powar et al., 2012; Wood et al., 2016; Wu et al., 2013; Zhang et al., 2012). It can also influence the light-harvesting efficiency and carrier transport kinetics of the p-DSSC. For example, nanocrystalline NiO films with low specific surface area showed relative low transparency and light absorption. Fewer dye molecules can attach onto $\mathrm{NiO}$ surface, affecting the light absorption ability, and it also reduces the light penetration depth and the short-circuit current density. Furthermore, it has a negative effect on the carrier transport path, for which there would be much more traps to capture the carriers.

Porous structures have shown promising results to suppress the recombination and enhance light absorption efficiency (Lepleux et al., 2009; Powar et al., 2012; Qu, 2016; Qu et al., 2013; Wu et al., 2013). Especially, hollow spherical structures with defined boundaries and interior cavities showed several advantageous as an electrode material. In addition to its low mass, the high pore volume and large specific surface area of hollow spheres (HSs) enhance the ability to absorb more dye. Also, HS has excellent light scattering effect, extended holding time for the incident light, more light can be harvested because of the multiple reflections that occur in the interior cavities (Bai et al., 2017; Dou et al., 2019; Jiang et al., 2018; Lai et al., 2012; Liao et al., 2015; Liu et al., 2012; Qian et al., 2009; Wang et al., 2019; Yang et al., 2014; Zuo 
et al., 2016). Besides, HS's short carrier-transport length and the porous structure can facilitate the liquid electrolyte diffusion, which accelerates the carrier transfer kinetics.

In this article, we introduce a novel triple-shell NiO HS using facial and scalable hydrothermal process. We show that it was possible to produce single, double and triple-shell HS in one single step by controlling the hydrothermal process parameters. The new triple-shell HS structure showed excellent light absorption ability with high photoelectrical efficiency of $1.79 \%$ when used as a photocathode. The details of the light absorption and photoelectrical performance are discussed in this article.

\section{Experimental section}

\subsection{Material synthesis}

To prepare single-shell $\mathrm{NiO} \mathrm{HS}$, about $2.5 \mathrm{~g}$ of glucose and $2.5 \mathrm{~g}$ of $\mathrm{Ni}\left(\mathrm{NO}_{3}\right)_{2} \cdot 6 \mathrm{H}_{2} \mathrm{O}$ were dissolved in $75 \mathrm{ml}$ of distilled water. The $\mathrm{pH}$ value was adjusted to 11.4 by adding aqueous ammonia. The obtained solution was transferred to the Teflon-lined autoclave and heated at $150{ }^{\circ} \mathrm{C}$ for $6 \mathrm{~h}$. The product was collected and rinsed with distilled water. After drying at $80^{\circ} \mathrm{C}$ for $12 \mathrm{~h}$, the as-prepared sample was calcined at $500{ }^{\circ} \mathrm{C}$ for $4 \mathrm{~h}$ in air. To prepare double and triple-shell $\mathrm{HS}$, the $\mathrm{pH}$ values were adjusted to 11.1 and 10.8 , respectively.

\subsection{Materials Characterization}

The crHSs' ystal structure and morphology ofre identified using X-ray diffraction (XRD, Rigaku D/max-2500), and transmission electron microscopy (TEM, 
JEM-2100). The chemical bonds and the valence states were determined using X-Ray photoelectron spectroscopy (XPS, VG Scientific ESCALAB 220IXL). The specific surface area and porosity were evaluated by nitrogen physisorption at $77.3 \mathrm{~K}$ recorded using NOVA 2000e (Quantachrome, Boynton Beach, FL, USA). UV-vis diffuse reflectance and absorption spectra were recorded on a UV 2450 spectrophotometer.

\subsection{Photoelectrical performance}

A compact NiO layer was first coated on FTO by a megnetron sputtering method. A second light scattering $\mathrm{NiO}$ layer was covered on the compact $\mathrm{NiO}$ layer by doctor blade method. The prepared two-layered $\mathrm{NiO}$ films were sintered at $450{ }^{\circ} \mathrm{C}$ for $0.5 \mathrm{~h}$. After cooling down to room temperature, the prepared photocathodes were immersed into the PMI-6T-TPA dye solution (0.2 $\mathrm{mM}$ in DMF). The as-prepared photocathode and the platinized counter electrode were sealed with electrolyte filling. The electrolyte used was composed of $0.07 \mathrm{M}\left[\mathrm{Co}(\mathrm{en})_{3}\right]\left(\mathrm{BF}_{4}\right)_{3}, 0.3 \mathrm{M}\left[\mathrm{Co}(\mathrm{en})_{3}\right]\left(\mathrm{BF}_{4}\right)_{2}, 0.1$ M lithium bis (trifluoromethanesulfonylimide) (LiTFSI) in acetonitrile. A $0.16 \mathrm{~cm}^{2}$ active electrode area was employed. Zahner CIMPS-2 electrochemical workstation together with a Trusttech CHF-XM-500W source under simulated Sun illumination

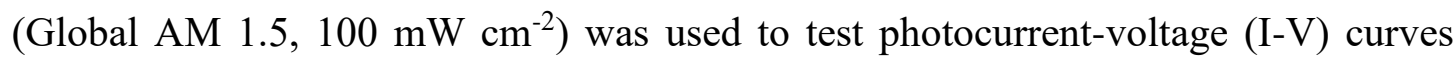
and electrochemical impedance spectra (EIS) $(100 \mathrm{kHz}$ to $0.1 \mathrm{~Hz}, 10 \mathrm{mV}$ perturbation). The incident photon-to-electron conversion efficiency (IPCE) experiments were performed using a system consisting of a Xe lamp $(300 \mathrm{~W})$ with a monochromator (Oriel 74100, Newport Corp., Irvine, CA, USA). 
(a)

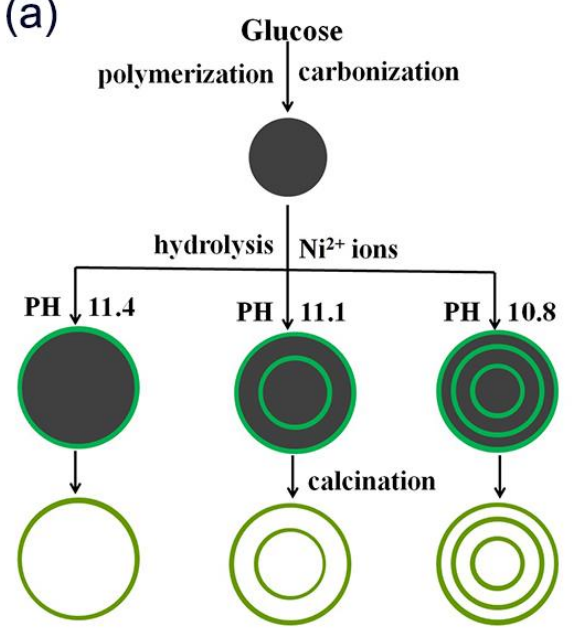

(b)

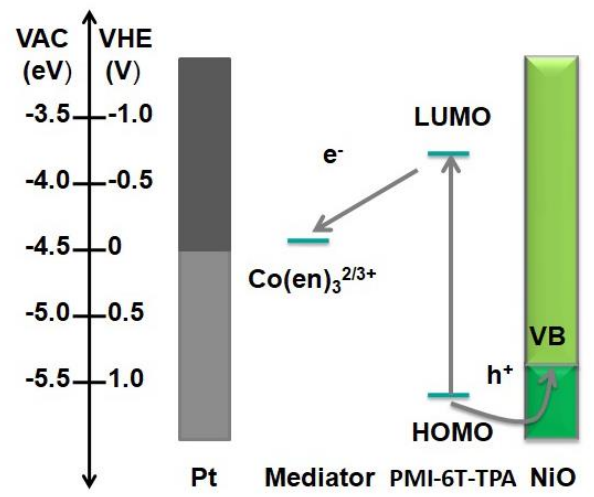

Scheme 1. (a) The structural formation processes of the single, double and triple-shell NiO HSs via a facile, one-step thermal treatment; (b) Energy level diagram for the as-prepared p-DSSC.

\section{Results and discussions}

As reported previously, the reaction rate, temperature, chelating reagent, precursor solution concentration, and the solution $\mathrm{pH}$ value play a curial rule on the morphology of the metal oxide and their assembly into 3D architectures. In the present work, ammonium aqueous was used to control the $\mathrm{pH}$ value of the precursor solution and further the morphology of NiO. The HS synthesis process is illustrated schematically in Scheme 1a. After adding ammonia to the solution, $\left[\mathrm{Ni}\left(\mathrm{NH}_{3}\right)_{\mathrm{x}}\right]^{2+}$ complexes are formed. During the hydrothermal treatment step, through dehydration and polymerization reactions, carbon spheres are produced from glucose, rich with $-\mathrm{OH}$ functional groups on the surface (Tang et al., 2016; Wang et al., 2016). These carbon spheres act as templates for the metal particles in the subsequent steps. Meanwhile, $\left[\mathrm{Ni}\left(\mathrm{NH}_{3}\right)_{\mathrm{x}}\right]^{2+}$ ions decompose gradually by hydrothermal treatment and release $\mathrm{Ni}^{2+}$, which then attach to the carbon spheres' surface by reacting with the -OH functional groups. This leads to the formation of a uniform metal hydroxide@carbon sphere 
core-shell structure. When the $\mathrm{pH}$ value kept at 10.8 , metal hydroxide or the $\mathrm{Ni}^{2+}$ on the surface of the carbonaceous particles may attract the -OH groups formed via the dehydration and polymerization of the glucose, forming the secondary carbon shell outside the first $\mathrm{Ni}(\mathrm{OH})_{\mathrm{x}}$ layer. Subsequently, new $\mathrm{Ni}^{2+}$ ions would attach onto the secondary carbon shell and finally the third carbon shell and $\mathrm{Ni}(\mathrm{OH})_{\mathrm{x}}$ layer. At $\mathrm{pH}$ values higher than 11.4 , the solution appears strong alkaline, the decomposition speed of $\left[\mathrm{Ni}\left(\mathrm{NH}_{3}\right)_{\mathrm{x}}\right]^{2+}$ increased, leading to a high growth rate and strong aggregation behaviour of the crystal nuclei. As a result, the amount of $\mathrm{Ni}^{2+}$ ions consumed quickly, and no more new particles can be anchored on the secondary or the third carbon shell. In summary, the carbon sphere and metal hydroxide are assembled shell by shell through a chemically induced dehydration process to form multi-shell $\mathrm{NiO} \mathrm{HS}$ precursors.

An energy-level diagram for the as-prepared p-DSSC is shown in Scheme 1b. The prepared $\mathrm{NiO}$ valence band is $0.80 \mathrm{~V}$ vs $\mathrm{NHE}(-5.30 \mathrm{eV}$ vs VAC) tested by UPS spectra. A Cobalt(II)/(III) electrolyte $(-0.025 \mathrm{~V}$ vs NHE, $-4.48 \mathrm{eV}$ vs VAC) was applied in our devices with a theoretical photovoltage of $0.825 \mathrm{~V}$, which is much larger than that of typical I-/I ${ }^{-}$electrolytes. PMI-6T-TPA dye with high-lying HOMO level of $1.1 \mathrm{~V}$ vs NHE was used, which indicates an efficient hole injection into $\mathrm{NiO}$ valence band. The LUMO level of PMI-6T-TPA is $-0.7 \mathrm{~V}$ vs NHE, which can be effectively regenerated by the electrolyte. 


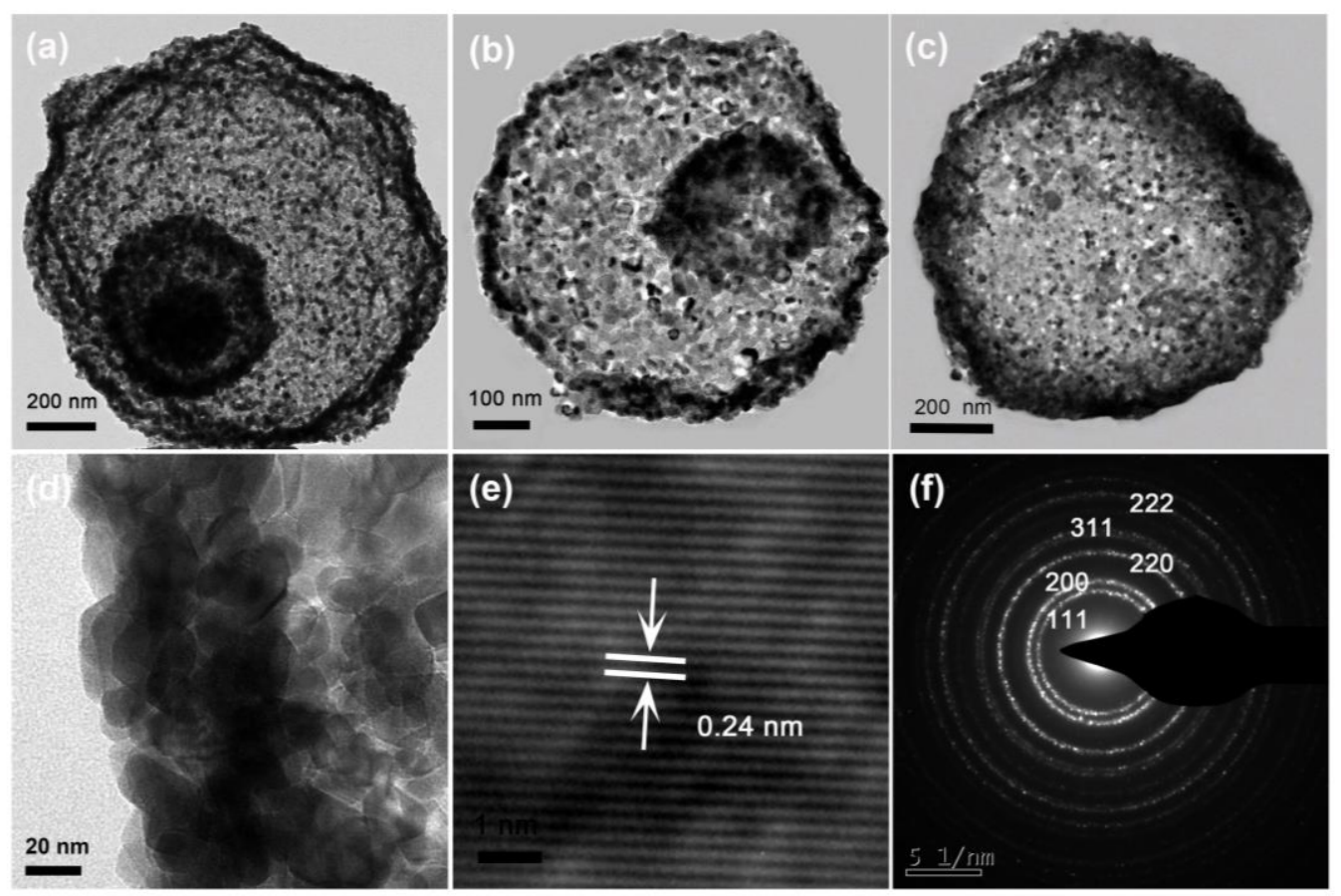

Fig. 1. TEM images of triple-shell $\mathrm{NiO}$ HS (a) (d), double-shell NiO HS (b) and single-shell NiO HS (c); HR-TEM images (e) of triple-shell NiO HS; selected area electron diffraction (SAED) pattern (f) of triple-shell NiO HS.

Transmission electron microscopy (TEM) images in Fig. 1a-f confirm the role of controlling the $\mathrm{pH}$ values on the number of shells. When the $\mathrm{pH}$ value adjusted to 10.8 by aqueous ammonia, triple-shell NiO HS was obtained. The outer HS diameter is about $1.2 \mu \mathrm{m}$, and the shell thickness is about $60 \mathrm{~nm}$ (Fig. 1a and 1d). The internal spheres can move freely within the outer microsphere (Wang et al., 2019). Fig. 1b shows a typical example of the double-shell $\mathrm{NiO} \mathrm{HS}$ prepared by fixing the $\mathrm{pH}$ value at 11.1. The outer diameter of the double-shell HS (about $0.9 \mu \mathrm{m}$ ) is slightly less than the triple-shell HS, and the thickness of the outer shell is also less (40 nm). The diameter of the internal sphere is about $300 \mathrm{~nm}$. The single-shell NiO HS obtained at high $\mathrm{pH}$ value is shown in Fig. 1c. The single-shell HS diameter is almost the same as that of the double-shell $\mathrm{NiO} \mathrm{HS}$, and the shell thickness is about $80 \mathrm{~nm}$. The 
high-resolution TEM (HRTEM) image (Fig. 1e) of a triple-shell NiO HS shows clear lattice fringe with a spacing of $0.24 \mathrm{~nm}$, corresponding to the (111) of NiO. The selected area electron diffraction (SAED) pattern of a triple-shell NiO HS is shown in Fig. 1f. The diffraction rings from inside to outside index to (111), (220), (200), (311) and (222), typical for the cubic phase of $\mathrm{NiO}$ (Qu et al., 2020; Zhang et al., 2011). 

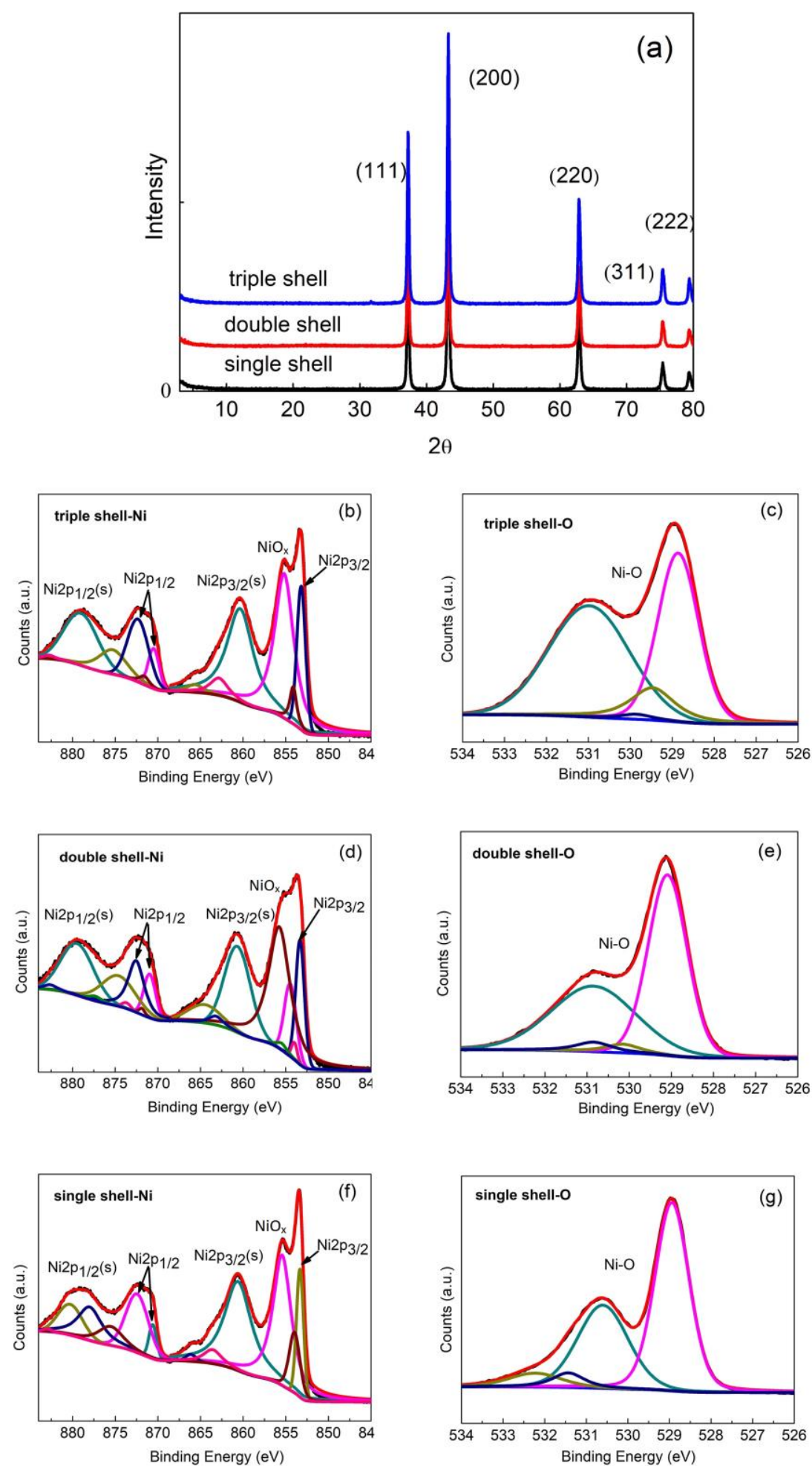

Fig. 2. (a) XRD pattern of the three NiO HSs; (b) Ni 2p XPS spectra of triple-shell NiO HS; (c) O 1s XPS spectra of triple-shell NiO HS; (d) Ni 2p XPS spectra of double-shell NiO HS; (e) O 1s XPS spectra of double-shell NiO HS; (f) Ni 2p XPS spectra of single-shell NiO HS; (g) O 1s XPS spectra of single-shell NiO HS. 
The phase structures of the prepared HSs are investigated further using X-ray diffractions (XRD). Fig. 2a shows the XRD traces of the three prepared samples. The five diffraction peaks at $2 \theta=37,42,61.8,75.7$ and $79^{\circ}$ can be indexed to (111), (200), (220), (311) and (222) crystal planes of cubic NiO (JCPDS 44-1159), in agreement with the SAED result (Fig. 1f). The sharp intensities of all peaks indicate the prepared HSs are of high crystallization quality. The crystallite sizes calculated by the Scherrer equation are almost the same for the three samples.

The electronic structure and composition of the NiO HSs are analyzed using X-Ray photoelectron spectroscopy (XPS). The high-resolution XPS spectra of O 1s and Ni $2 p$ are given in Fig. $2 b-g$. The Ni $2 p$ spectra comprise two regions for Ni $2 p_{3 / 2}$ $(850-865 \mathrm{eV})$ and $\mathrm{Ni} 2 \mathrm{p}_{1 / 2}(870-885 \mathrm{eV})$ spin-orbit levels. The Ni $2 \mathrm{p}_{3 / 2}$ can be fitted with several peaks corresponding to two oxidation states of nickel, $\mathrm{Ni}$ (II) and $\mathrm{Ni}(\mathrm{III})$. The peak at $854.3 \mathrm{eV}$ from $\mathrm{Ni}^{2+}$ is associated with the Ni-O octahedral bonding of cubic rock salt $\mathrm{NiO}$ (Qu et al., 2020; Tan et al., 2019; Wang et al., 2016), which is the same for the $\mathrm{O} 1 \mathrm{~s}$ peak at $529.3 \mathrm{eV}$. The peak at $855.7 \mathrm{eV}$ together with $\mathrm{O} 1 \mathrm{~s}$ peak at $531 \mathrm{eV}$ are from the $\mathrm{Ni}^{2+}$-vacancy induced $\mathrm{Ni}^{3+}$ ion. It can be concluded from $\mathrm{Ni} 2 \mathrm{p}$ spectra that the content of $\mathrm{Ni}^{3+}$ is quite large and the calculated proportion is $29.3 \%$, $29.9 \%$ and $34.3 \%$ for single-, double-, and triple-shell NiO HS, respectively. The existing $\mathrm{Ni}^{3+}$ ions can increase p-type conductivity in the $\mathrm{NiO}_{x}$ film (Kwon et al., 2016; Mrowec and Grzesik, 2004; Qu et al., 2020) favourable for hole transport. Furthermore, it would modify the hole transport kinetics, reduce the hole recombination and improve the charge collection. 

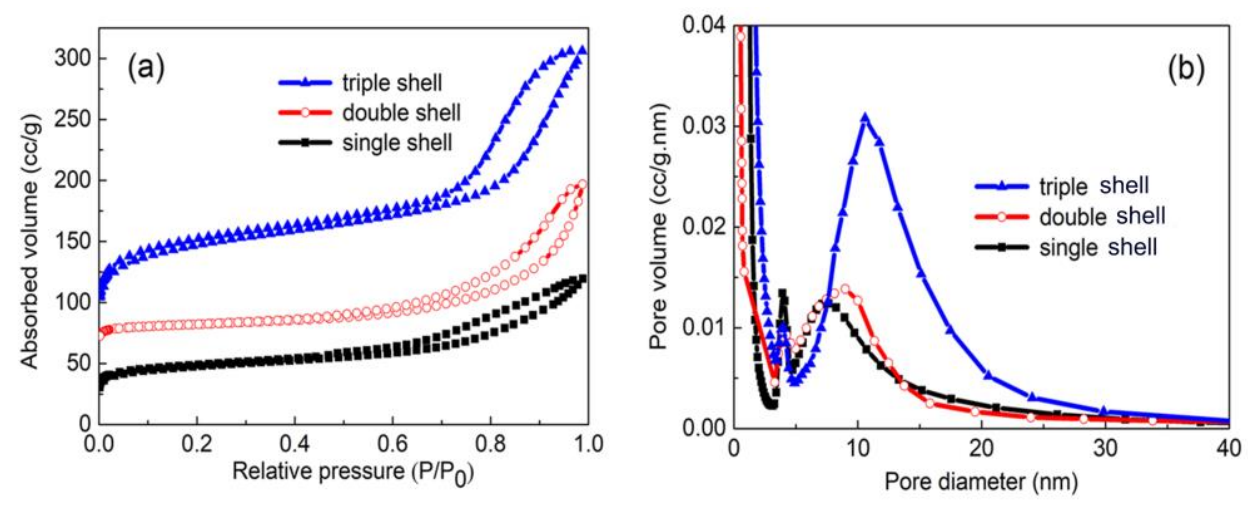

Fig. 3. (a) $\mathrm{N}_{2}$ adsorption-desorption isotherms of the three samples; (b) the corresponding pore size distribution of the samples.

The specific surface area and pore size distribution are measured using $\mathrm{N}_{2}$ adsorption-desorption experiments. The BET surface areas of the triple, double and single-shell NiO HSs are 465, 271, $167 \mathrm{~m}^{2} / \mathrm{g}$, respectively. The high surface area should facilitate dye adsorption on the $\mathrm{NiO}$ surface. The $\mathrm{N}_{2}$ adsorption-desorption isotherms (Fig. 3a) shows loops with hysteresis for all the three samples under the relative pressure $\left(\mathrm{P} / \mathrm{P}_{0}\right)$ ranging from $0.7-1.0$, indicating the presence of well-defined mesoporous structure (Zoromba et al., 2017). A sharper capillary condensation step at higher pressure is observed for triple-shell $\mathrm{NiO} \mathrm{HS}$, suggesting larger mesopores than the other two samples. The pore size distributions are presented in Fig. 3b. For all HS, there are two mean pore sizes peaks. The two peaks of the triple-shell NiO HS are centred at around 4 and $11.5 \mathrm{~nm}$, associated with the mesopores among nano-thorns and the large voids from the hollow interiors, respectively. The obvious right shift in the larger pores peak is probably due to the increase in the internal voids when forming the triple-shells. Since $\left[\mathrm{Co}(\mathrm{en})_{3}\right]$ ion is larger than the traditional iodine ion, 
the large pore size is believed to be much more beneficial for the penetration of the electrolyte and dye molecule into the $\mathrm{NiO}$ film.
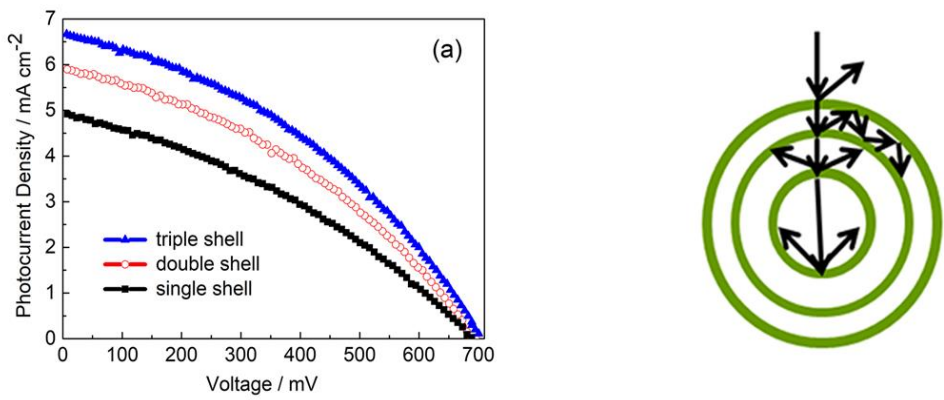

(b)
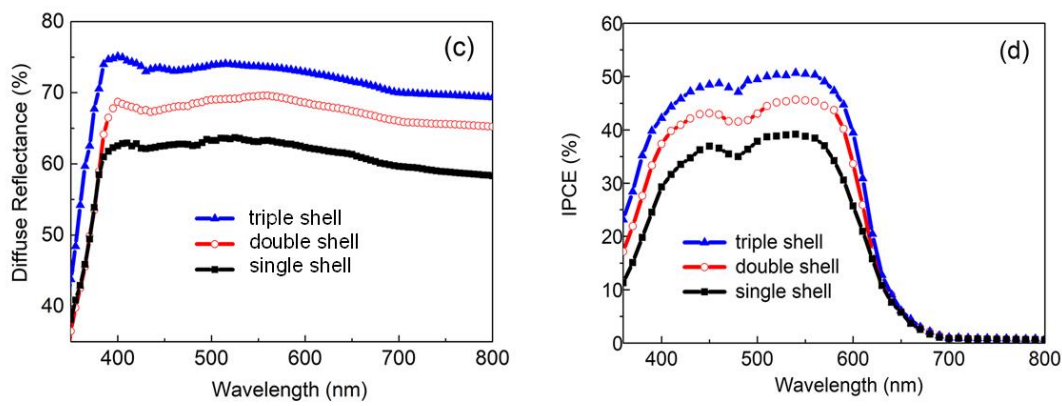

Fig. 4. (a) J-V curves of p-DSSCs based on NiO HS photocathodes; (b) a schematic light pathway illustration of triple-shell NiO HS; (c) diffuse Reflectance spectra of NiO HSs; (d) IPCE spectra of NiO HSs sensitized by PMI-6T-TPA dye.

Table 1. Detailed photovoltaic parameters of the as-prepared p-DSSCs.

\begin{tabular}{lcccc}
\hline & $\boldsymbol{J}_{\mathbf{s c}}\left(\mathbf{m A ~ \mathbf { ~ c m } ^ { - 2 } )}\right.$ & $\boldsymbol{V}_{\mathbf{o c}}(\mathbf{m V})$ & $\boldsymbol{F F}$ & $\boldsymbol{\eta}(\mathbf{c})$ \\
\hline Single shell & 4.92 & 689 & 0.35 & 1.18 \\
\hline Double shell & 5.90 & 695 & 0.37 & 1.51 \\
\hline Triple shell & 6.67 & 700 & 0.38 & 1.79 \\
\hline
\end{tabular}

We then examined the three different $\mathrm{NiO}$ HSs as photocathodes to assemble p-DSSCs. The photoelectrical performances are shown in Fig. 4 and Table 1. A high short-circuit photocurrent density $\left(J_{s c}\right)$ of $6.67 \mathrm{~mA} \mathrm{~cm}^{-2}$ is observed for triple-shell 
$\mathrm{NiO}$ HS based p-DSSC, which is higher than both single and double-shell NiO HSs (4.92 $\mathrm{mA} \mathrm{cm}^{-2}$ and $5.90 \mathrm{~mA} \mathrm{~cm}{ }^{-2}$, respectively). The photovoltage $\left(V_{o c}\right)$ values of the three solar cells can reach up to $700 \mathrm{mV}$, with only a little difference between the three nanostructures. It is worth noting that coupled with $\mathrm{Co}^{2+/ 3+}$ electrolyte the $V_{o c}$ values (with a theoretical photovoltage of $0.825 \mathrm{~V}$ ) are higher than with $\mathrm{I}^{-} / \mathrm{I}^{-}$ electrolyte. The fill factors $(F F)$ show a direct proportion to the $J_{s c}$ and $V_{o c}$ values. The corresponding efficiencies are calculated to be $1.79,1.51$ and $1.18 \%$ for the triple, double and single-shell NiO HSs, respectively. From the above results, it can be concluded that both the short-circuit current density and the overall energy conversion efficiency of solar cells increase with the number of shells. This improvement can be attributed to the high specific surface area, which facilitates the dye absorption and enables multiple light reflection and scattering between spherical shells, as illustrated in Fig. 4b. The synergic effect of the multiple light reflection and the high dye absorption leads to an improved light-harvesting and thus increase the short-circuit current density of solar cells. Besides, larger pore size is beneficial for the penetration of the larger $\left[\mathrm{Co}(\mathrm{en})_{3}\right]$ electrolyte molecule, which can quickly react with the deoxidized dyes. The recombination can be effectively compressed, and a superior hole transport can be expected, which lead to an improved FF and further a higher energy conversion efficiency. The triple shells HS efficiency is higher than most reported p-DSSCs sensitized by PMI-6T-TPA, as presented in Table 2.

The diffuse reflectance of different NiO HSs is tested to investigate the scattering abilities. As illustrated in Fig. 4c, triple-shell NiO HS shows the strongest reflectance 
of light over the range of 400-800 nm. Double and single-shell NiO HSs are lower, but their reflectance values are all above $50 \%$. Multi-shell NiO HS presents multiple reflection and scattering between the shells. Furthermore, the inner cavities have to lead to enhanced light capturer to confine the incident light, enhancing the light-harvesting and current density.

The incident-photon-to-current efficiency (IPCE) spectra of the PMI-6T-TPA -sensitized solar cells are shown in Fig. 4d in the range from 350 to $800 \mathrm{~nm}$, providing further evidence on the scattering effect of the multi-shell structures. The maximum IPCE values of all the cells are more than $30 \%$, which is very high for p-DSSCs (Liu et al., 2015a; Nattestad et al., 2008). Triple-shell NiO HS shows the highest IPCE over the entire wavelength region, which is in agreement with the diffuse reflectance and observed $\mathrm{J}_{\mathrm{sc}}$ values. It is worth noting that the IPCE data of triple-shell NiO HS shows a slightly red-shift to a longer wavelength compared to the other two HSs due to the better light-scattering ability.

Table 2. Efficiency of p-DSSCs sensitized by PMI-6T-TPA dye in previous reports and present work.

\begin{tabular}{|c|c|c|c|}
\hline Photoanode & Electrolyte & Efficiency (\%) & Reference \\
\hline $\mathrm{NiO}$ & {$\left[\mathrm{Fe}(\mathrm{acac})_{3}\right]^{0 / 1-}$} & 2.51 & (Perera et al., 2015) \\
\hline $\mathrm{NiO}$ & {$\left[\mathrm{Co}(\mathrm{en})_{3}\right]^{3+/ 2+}$} & 1.30 & (Powar et al., 2013) \\
\hline $\mathrm{NiO}$ microballs & $\mathrm{I}^{-} / \mathrm{I}_{3}^{-}$ & 0.46 & (Powar et al., 2012) \\
\hline $\begin{array}{c}\mathrm{CuCrO}_{2} \text { nanoparticles } \\
\mathrm{NiO} \\
\end{array}$ & $\begin{array}{l}{\left[\mathrm{Co}(\text { en })_{3}\right]^{3+/ 2+}} \\
{\left[\mathrm{Co}(\text { en })_{3}\right]^{3+/ 2+}}\end{array}$ & $\begin{array}{l}0.48 \\
1.00 \\
\end{array}$ & (Powar et al., 2014) \\
\hline $\mathrm{NiO}$ & Thiolate electrolyte & 0.51 & (Qu et al., 2020) \\
\hline $\mathrm{NiO} / \mathrm{CMK}-3$ & {$\left[\mathrm{Co}(\mathrm{en})_{3}\right]^{3+/ 2+}$} & $1.48 \%$ & (Powar et al., 2015) \\
\hline Triple-shell NiO HS & {$\left[\mathrm{Co}(\mathrm{en})_{3}\right]^{3+/ 2+}$} & $1.79 \%$ & This work \\
\hline
\end{tabular}




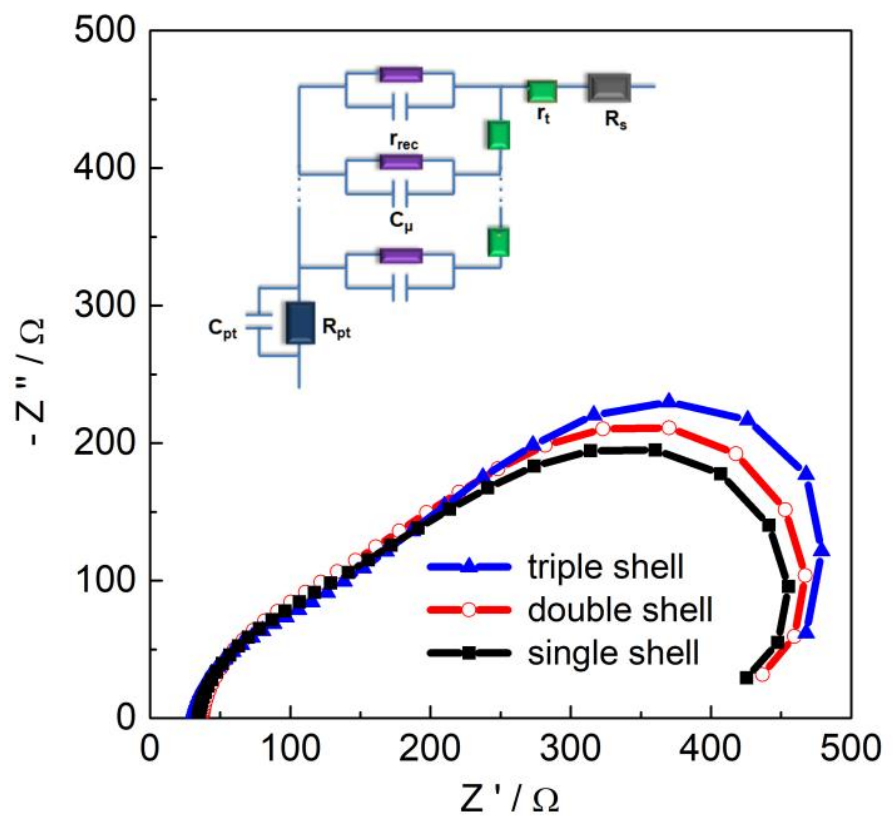

Fig. 5. Nyquist plots of p-DSSCs made of the prepared HSs. The inset shows the equivalent circuit for the impedance spectrum. $R_{s}$ : serial resistance; $R_{t}$ : transport resistance of the film; $R_{\text {rec }}$ : the recombination resistance of the film; $R_{p t}$ : charge-transfer resistance of Pt electrode; $C_{\mu}$ : distributed capacitance of p-semiconductor; $C_{p t}$ : the double-layer capacitance of the platinized counter electrode.

To further understand the three HS-based cells' electrical characteristics, EIS measurements (Fig. 5) are conducted under open circuit and 1 sun intensity conditions. Two semicircles extending from total resistance can be recognized; (i) one semicircle at high frequency attributed to the charge exchange process at the Pt electrode interface $\left(R_{p t}\right)$, (ii) the semicircle at low frequency attributed to the hole transport in the semiconductor film $\left(R_{t}\right)$ and the back reaction at the semiconductor/dye/electrolyte interface $\left(R_{\text {rec }}\right)$ (Liu et al., 2015b; Qu et al., 2020; Tan et al., 2019). Equivalent circuit inset in the figure is used for the EIS tests fitting and the parameters. As shown in Table 3, the three samples' charge exchange processes are slightly different, for which the $R_{p t}$ value of triple-shell NiO HS is lower, indicating fast electrolyte oxidization. 
The triple-shell NiO HS hierarchical structure facilitates the electrolyte penetration and electrode wetting, leading to a fast reaction of the reductive dyes and oxidized electrolyte, subsequently a fast reaction of reductive electrolyte and holes from $\mathrm{Pt}$ electrode. The $R_{r e c}$ is the charge-transfer resistance of hole recombination at the $\mathrm{NiO} /$ electrolyte interfaces. High value over $330 \Omega$ is fitted for all three samples, indicating prohibited recombination at the $\mathrm{NiO} /$ dye/electrolyte interface. It can be observed that the triple-shell NiO HS shows slightly higher $R_{r e c}$ value than other HS, indicating lower recombination due to the quick reactions between the electrolyte and the deoxidized dyes, and the oxidized electrolyte and holes. An improved hole transport can also be observed for the three materials. The charge collection efficiency $\left(\eta_{c c}\right)$ can be calculatd from $R_{r e c}$ and $R_{t}$ values. And an enhanced charge collection efficiency of $81.3 \%$ is observed for triple-shell NiO HS. Finally, the generated holes can be transported quickly along with the shell of the sphere and collected at the bottom of the sphere. Superior transport is provided by such a unique structure, reducing the transport time and further reducing the recombination.

Table 3. Fitted and calculated data from EIS spectra of the as-prepared p-DSSCs.

\begin{tabular}{lcccc}
\hline & $\boldsymbol{R}_{\boldsymbol{p t}}(\Omega)$ & $\boldsymbol{R}_{\boldsymbol{t}}(\Omega)$ & $\boldsymbol{R}_{\boldsymbol{r e c}}(\mathbf{\Omega})$ & $\boldsymbol{\eta}_{\boldsymbol{c c}}(\mathbf{\%})$ \\
\hline Single shell & 66 & 69 & 332 & 79.2 \\
\hline Double shell & 60 & 69 & 343 & 79.9 \\
\hline Triple shell & 49 & 68 & 364 & 81.3 \\
\hline
\end{tabular}

\section{Conclusions}

In summary, triple, double and single-shell $\mathrm{HS}$ of $\mathrm{NiO}_{\mathrm{x}}$ were prepared through a 
one-step hydrothermal process. Such HSs possess large surface area and show enhanced ability to absorb dye molecules. The novel triple-shell NiO HS with its unique hierarchal structure exhibited excellent light reflection and scattering ability. Together with more inner cavities to confine the incident light, the light-harvesting was greatly improved. High photoelectrical efficiency of $1.79 \%$ was obtained using triple-shell $\mathrm{NiO} \mathrm{HS}$ as photocathode material. The EIS measurement also indicates fast dye regeneration, improved hole transport and lower recombination, contributing to the superior photoelectrical performance.

\section{Declaration of Competing Interest}

The authors declare no conflict of interest.

\section{Acknowledgements}

This article was funded by the Research Foundation of Hunan Education Committee of China (grant number 18C0033) and the Science and Technology Project of Changsha City (grant number kq1907133).

\section{References}

Awais, M., Dowling, D.D., Rahman, M., Vos, J.G., Decker, F., Dini, D., 2012. Spray-deposited $\mathrm{NiO}_{\mathrm{x}}$ films on ITO substrates as photoactive electrodes for p-type dye-sensitized solar cells. J. Appl. Electrochem. 43 (2), 191-197.

Bai, J., Sun, X., Han, G., Diao, G., 2017. Double-shell $\mathrm{CeO}_{2} @ \mathrm{TiO}_{2}$ hollow spheres composites with enhanced light harvesting and electron transfer in dye-sensitized solar cells. J. Alloys Compd. 722, 864-871.

Bonomo, M., Dini, D., Decker, F., 2018. Electrochemical and Photoelectrochemical Properties of Nickel Oxide (NiO) With Nanostructured Morphology for Photoconversion Applications. Front. Chem. 6, 601.

Dou, J., Li, X., Li, Y., Chen, Y., Wei, M., 2019. Fabrication of $\mathrm{Zn}_{2} \mathrm{SnO}_{4}$ microspheres with 
controllable shell numbers for highly efficient dye-sensitized solar cells. Sol. Energy 181, 424-429.

Grätzel, M., 2001. Photoelectrochemical cells. Nature 414 (6861), 338-344.

Jiang, Y., Qian, X., Zhu, C., Liu, H., Hou, L., 2018. Nickel Cobalt Sulfide Double-Shelled Hollow

Nanospheres as Superior Bifunctional Electrocatalysts for Photovoltaics and Alkaline Hydrogen Evolution. ACS Appl. Mater. Inter. 10 (11), 9379-9389.

He, J.J., Lindström, H., Hagfeldt, A., Lindquist, S.E., 1999. Dye-sensitized nanostructured tandem cell-first demonstrated cell with a dye-sensitized photocathode. Sol. Energ. Mat. Sol. C 62 (3), 265-273.

He, J.J., Lindström, H., Hagfeldt, A., Lindquist, S.E., 1999. Dye-Sensitized Nanostructured p-Type Nickel Oxide Film as a Photocathode for a Solar Cell. J. Phys. Chem. B 103, 8940-8943.

Lai, X., Halpert, J.E., Wang, D., 2012. Recent advances in micro-/nano-structured hollow spheres for energy applications: From simple to complex systems. Energ. Environ. Sci. 5 (2), 5604-5618.

Lepleux, L., Chavillon, B., Pellegrin, Y., Blart, E., Cario, L., Jobic, S., Odobel, F., 2009. Simple and reproducible procedure to prepare self-nanostructured $\mathrm{NiO}$ films for the fabrication of P-type dye-sensitized solar cells. Inorg. Chem. 48 (17), 8245-8250.

Liao, W., Zheng, D., Tian, J., Lin, Z., 2015. Dual-functional semiconductor-decorated upconversion hollow spheres for high efficiency dye-sensitized solar cells. J. Mater. Chem. A 3 (46), 23360-23367.

Liu, Q., Wei, L., Yuan, S., Ren, X., Zhao, Y., Wang, Z., Zhang, M., Shi, L., Li, D., 2015a. The effect of $\mathrm{Ni}\left(\mathrm{CH}_{3} \mathrm{COO}\right)_{2}$ post-treatment on the charge dynamics in p-type $\mathrm{NiO}$ dye-sensitized solar cells. J. Mater. Sci. 50 (20), 6668-6676.

Liu, Q., Wei, L., Yuan, S., Ren, X., Zhao, Y., Wang, Z., Zhang, M., Shi, L., Li, D., Li, A., $2015 b$. Influence of interface properties on charge density, band edge shifts and kinetics of the photoelectrochemical process in p-type NiO photocathodes. RSC Adv. 5 (88), 71778-71784.

Liu, Y., Wang, S., Shan, Z., Li, X., Tian, J., Mei, Y., Ma, H., Zhu, K., 2012. Anatase $\mathrm{TiO}_{2}$ hollow spheres with small dimension fabricated via a simple preparation method for dye-sensitized solar cells with an ionic liquid electrolyte. Electrochim. Acta 60, 422-427.

Mansha, M., Younas, M., Gondal, M.A., Ullah, N., 2019. 1,5-Naphthyridine-based conjugated polymers as co-sensitizers for dye-sensitized solar cells. Sol. Energy 194, 682-687.

Nattestad, A., Ferguson, M., Kerr, R., Cheng, Y.B., Bach, U., 2008. Dye-sensitized nickel (II) oxide photocathodes for tandem solar cell applications. Nanotechnology 19 (29) , 295304.

Nattestad, A., Mozer, A.J., Fischer, M.K., Cheng, Y.B., Mishra, A., Bauerle, P., Bach, U., 2010. Highly efficient photocathodes for dye-sensitized tandem solar cells. Nat. Mater. 9 (1), 31-35.

Naveen Kumar, T.R., Yuvaraj, S., Kavitha, P., Sudhakar, V., Krishnamoorthy, K., Neppolian, B., 2020. Aromatic amine passivated $\mathrm{TiO}_{2}$ for dye-sensitized solar cells (DSSC) with $\sim 9.8 \%$ efficiency. Sol. Energy 201, 965-971.

Perera, I.R., Daeneke, T., Makuta, S., Yu, Z., Tachibana, Y., Mishra, A., Bauerle, P., Ohlin, C.A., Bach, U., Spiccia, L., 2015. Application of the tris(acetylacetonato)iron(III)/(II) redox couple in p-type dye-sensitized solar cells. Angew. Chem. Int. Ed. 54 (12), 3758-3762.

Powar, S., Bhargava, R., Daeneke, T., Götz, G., Bäuerle, P., Geiger, T., Kuster, S., Nüesch, F.A., Spiccia, L., Bach, U., 2015. Thiolate/Disulfide Based Electrolytes for p-type and Tandem 
Dye-Sensitized Solar Cells. Electrochim. Acta 182, 458-463.

Powar, S., Daeneke, T., Ma, M.T., Fu, D., Duffy, N.W., Gotz, G., Weidelener, M., Mishra, A., Bauerle, P., Spiccia, L., Bach, U., 2013. Highly efficient p-type dye-sensitized solar cells based on tris(1,2-diaminoethane)cobalt (II)/(III) electrolytes. Angew. Chem. Int. Ed. 52 (2), 602-605.

Powar, S., Wu, Q., Weidelener, M., Nattestad, A., Hu, Z., Mishra, A., Bäuerle, P., Spiccia, L., Cheng, Y.-B., Bach, U., 2012. Improved photocurrents for p-type dye-sensitized solar cells using nano-structured nickel (ii) oxide microballs. Energ. Environ. Sci. 5 (10), 8896-8900.

Powar, S., Xiong, D., Daeneke, T., Ma, M.T., Gupta, A., Lee, G., Makuta, S., Tachibana, Y., Chen, W., Spiccia, L., Cheng, Y.-B., Götz, G., Bäuerle, P., Bach, U., 2014. Improved Photovoltages for p-Type Dye-Sensitized Solar Cells Using $\mathrm{CuCrO}_{2}$ Nanoparticles. J. Phys. Chem. C 118 (30), 16375-16379.

Qian, J., Liu, P., Xiao, Y., Jiang, Y., Cao, Y., Ai, X., Yang, H., 2009. TiO2-Coated Multilayered $\mathrm{SnO}_{2}$ Hollow Microspheres for Dye-Sensitized Solar Cells. Adv. Mater. 21(36), 3663-3667.

Qu, J., 2016. NiO Nano-Flower Sensitized by Perovskite as Photocathode for p-DSSC with Superior Hole Transfer Kinetics. Int. J. Electrochem. Sci., 7553-7561.

Qu, J., Fan, Z., Mira, H., Wang, J., Abdelkader, A.M., Ding, S., 2020. Hierarchical NiO/CMK-3 Photocathode for a p-Type Dye-Sensitized Solar Cell with Improved Photoelectrochemical Performance and Fast Hole Transfer. Molecules 25 (7), 1638.

Qu, J., Li, G.R., Gao, X.P., 2010. One-dimensional hierarchical titania for fast reaction kinetics of photoanode materials of dye-sensitized solar cells. Energ. Environ. Sci. 3 (12), 2003-2009.

Qu, J., Yang, Y., Wu, Q., Coxon, P.R., Liu, Y., He, X., Xi, K., Yuan, N., Ding, J., 2014. Hedgehog-like hierarchical $\mathrm{ZnO}$ needle-clusters with superior electron transfer kinetics for dye-sensitized solar cells. RSC Adv. 4 (22), 11430-11437.

Qu, Y., Zhou, W., Miao, X., Li, Y., Jiang, L., Pan, K., Tian, G., Ren, Z., Wang, G., Fu, H., 2013. A new layered photocathode with porous $\mathrm{NiO}$ nanosheets: an effective candidate for p-type dye-sensitized solar cells. Chem. Asian J. 8 (12), 3085-3090.

Tan, R., Wei, Z., Liang, J., Lv, Z., Chen, B., Qu, J., Yan, W., Ma, J., 2019. Enhanced open-circuit photovoltage and charge collection realized in pearl-like $\mathrm{NiO} / \mathrm{CuO}$ composite nanowires based p-type dye sensitized solar cells. Mater. Res. Bull. 116, 131-136.

Tang, J., Liu, J., Salunkhe, R.R., Wang, T., Yamauchi, Y., 2016. Nitrogen-doped hollow carbon spheres with large mesoporous shells engineered from diblock copolymer micelles. Chem. Commun. (Camb) 52 (3), 505-508.

Wang, X., Du, Y., Ma, J., 2016. Novel synthesis of carbon spheres supported nanoscale zero-valent iron for removal of metronidazole. Appl. Surf. Sci. 390, 50-59.

Wang, Y., Ma, C., Wang, C., Cheng, P., Xu, L., Lv, L., Zhang, H., 2019. Design of $\mathrm{SnO}_{2} @ \mathrm{Air} @ \mathrm{TiO}_{2}$ hierarchical urchin-like double-hollow nanospheres for high performance dye-sensitized solar cells. Sol. Energy 189, 412-420.

Wood, C.J., Summers, G.H., Clark, C.A., Kaeffer, N., Braeutigam, M., Carbone, L.R., D'Amario, L., Fan, K., Farre, Y., Narbey, S., Oswald, F., Stevens, L.A., Parmenter, C.D., Fay, M.W., La Torre, A., Snape, C.E., Dietzek, B., Dini, D., Hammarstrom, L., Pellegrin, Y., Odobel, F., Sun, L., Artero, V., Gibson, E.A., 2016. A comprehensive comparison of dye-sensitized NiO photocathodes for solar energy conversion. Phys. Chem. Chem. Phys. 18 (16), 10727-10738.

Wu, Q., Shen, Y., Li, L., Cao, M., Gu, F., Wang, L., 2013. Morphology and properties of NiO 
electrodes for p-DSSCs based on hydrothermal method. Appl. Surf. Sci. 276, 411-416.

Xi, J., Wu, Z., Xi, K., Dong, H., Xia, B., Lei, T., Yuan, F., Wu, W., Jiao, B., Hou, X., 2016. Initiating crystal growth kinetics of $\alpha-\mathrm{HC}\left(\mathrm{NH}_{2}\right)_{2} \mathrm{PbI}_{3}$ for flexible solar cells with long-term stability. Nano Energy 26, 438-445.

Xi, J., Xi, K., Sadhanala, A., Zhang, K.H.L., Li, G., Dong, H., Lei, T., Yuan, F., Ran, C., Jiao, B., Coxon, P.R., Harris, C.J., Hou, X., Kumar, R.V., Wu, Z., 2019. Chemical sintering reduced grain boundary defects for stable planar perovskite solar cells. Nano Energy 56, 741-750.

Yang, X., Luo, J., Zhou, L., Yang, B., Zuo, X., Li, G., Tang, H., Zhang, H., Wu, M., Ma, Y., Jin, S., Sun, Z., Chen, X., 2014. A novel Pt-free counter electrode for dye-sensitized solar cells: Nickel sulfide hollow spheres. Mater. Lett. 136, 241-244.

Zhang, X.L., Huang, F., Nattestad, A., Wang, K., Fu, D., Mishra, A., Bauerle, P., Bach, U., Cheng, Y.B., 2011. Enhanced open-circuit voltage of p-type DSC with highly crystalline NiO nanoparticles. Chem. Commun. (Camb) 47 (16), 4808-4810.

Zhang, X.L., Zhang, Z., Chen, D., Bauerle, P., Bach, U., Cheng, Y.B., 2012. Sensitization of nickel oxide: improved carrier lifetime and charge collection by tuning nanoscale crystallinity. Chem. Commun. (Camb) 48 (79), 9885-9887.

Zoromba, M.S., Abdel-Aziz, M.H., Bassyouni, M., Gutub, S., Demko, D., Abdelkader, A., 2017. Electrochemical Activation of Graphene at Low Temperature: The Synthesis of Three-Dimensional Nanoarchitectures for High Performance Supercapacitors and Capacitive Deionization. ACS Sustain. Chem. Eng. 5 (6), 4573-4581.

Zuo, X., Yan, S., Yang, B., Li, G., Zhang, H., Tang, H., Wu, M., Ma, Y., Jin, S., Zhu, K., 2016. Template-free synthesis of nickel sulfides hollow spheres and their application in dye-sensitized solar cells. Sol. Energy 132, 503-510. 